\title{
Analysis of a novel disc-type hybrid stepper motor with field circuit model
}

\author{
J KAVITHA $^{1, * \mathbb{D}}$ and B UMAMAHESWARI ${ }^{2}$ \\ ${ }^{1}$ Department of Electrical and Electronics Engineering, Rajalakshmi Engineering College, Chennai 602 105, \\ India \\ ${ }^{2}$ Department of Electrical and Electronics Engineering, College of Engineering Guindy, Anna University, \\ Chennai 600 025, India \\ e-mail: kavitha.j@rajalakshmi.edu.in; umamahesb@annauniv.edu
}

MS received 5 May 2017; revised 3 November 2018; accepted 25 February 2019; published online 13 April 2019

\begin{abstract}
This paper presents modelling and analysis of a novel disc-type hybrid stepper motor (DTHSM) and brings out its relative merits over the cylindrical version. The machine is characterized by winding free rotorand stator-placed field coils/permanent magnets, creating homopolar field. DTHSM has the advantage of providing independent space for the field and armature, while other stator field machines have to share the same core space for both the field and armature. This increases field strength both by permanent magnet as well as field coils to achieve increased torque and speed ranges. The machine parameters are obtained using a field circuit model and its performance is predicted using analytical equations. A 50-W, 200 steps DTHSM prototype is fabricated and tested. Aggregation of simulation and experimental results validates the effectiveness of the proposed configuration.
\end{abstract}

Keywords. Radial flux; axial flux; hybrid stepper motors; unipolar; equivalent magnetic circuit.

\section{Introduction}

Stepper motors are machines that translate switched excitation into incremental steps. These incremental motion devices are classified based on their construction as variable reluctance and permanent magnet (PM) machines. Combining both the types is the hybrid stepper motor (HSM), which is more suitable for high-resolution position applications. It provides smaller step angle than the variable reluctance machines. It also has higher torque producing capability for a given motor volume than its reluctance counterpart [1-3]. Of late, wherever axial compactness with better torque and power density is necessary, axial flux configurations are used. A complete literature review of axial flux machines is given in [4]. Major concerns in axial flux machines are

1. necessity for 3D FEM analysis and

2. structural complexity in the choice of laminations.

To overcome the need for 3D FEM analysis, which is time consuming, 2D FEM analysis with three different analytical approaches of using variable separation method, namely the mean radius, multi-slicing and Bessel function can be used [5]. To reduce the complexity in laminations,

*For correspondence the stator core can be of segmented armature lamination, yokeless or soft magnetic composite (SMC) material.

There has been continued interest to propose various popular machine topologies of cylindrical machines into axial flux configurations like, induction machines (IM), permanent magnet synchronous machines (PMSM), switched reluctance machines (SRM), brushless DC machines (BLDC) and synchronous reluctance machines [6-10] into axial form. Surprisingly no paper on extending the HSM in axial form has been attempted.

HSMs are characterized by homopolar field flux, position-sensorless operation and high torque capabilities. Positioning of field coil for homopolar behaviour in axial form is a challenge. In doubly excited machines, placing both the field and armature windings in the stator and relieving the rotor from holding any magnets and windings [11] is becoming popular for high-speed applications; further, placing of field coils/PMs in the stator enables better cooling. There are three types of configurations used in the machines where the PMs are placed in the stator yoke, namely doubly salient permanent magnet (DSPM) machines, switched flux permanent magnet (SFPM) machines and flux reversal permanent magnet (FRPM) machines [12-19]. Among them DSPM is homopolar, and the FRPM and SFPM are improved versions of it. All the machines have to compete for the space to place the PMs on the stator yoke $[20,21]$. 
Cylindrical HSMs has both radial and axial fluxes; hence, its disc form should have both radial and axial flux. In this work, a cylindrical HSM is cut open radially and spread out circumferentially to obtain a disc-type HSM with similar stepping angle. Also the PMs originally in the rotor of the cylindrical form are placed between two stator rings in the disc form HSM. This provides more space to locate the PMs separately rather than using them on the stator yoke. Also, switched homopolar excitation can be used to improve the torque capability and variable field excitation housing the field coils can be used instead of PMs.

A complete description on the topology of the proposed machine is presented in section 2. The description on the working principle of the machine both in the reluctance and HSM mode is explained in section 3. Equivalent circuit model, parameter prediction and dynamic response of the proposed disc-type hybrid stepper motor (DTHSM) are given, respectively, in section 4,5 and 6 . The prototype details with experimental results are discussed in section 7 .

\section{Description of proposed machine}

The proposed DTHSM is shown in figure 1. It is designed for $1.8^{\circ}$ stepping angle. The stator has two phases with 8 poles and the rotor has 50 teeth. Hence the number of poles in the stator has to be 8 . The stator and rotor are made of two concentric rings. The phase and field windings are stationary. The rotor does not house any windings. The stator and rotor have toothed structures. The rotor rings are affixed on a ferromagnetic disc while the stator rings are affixed on a non-ferromagnetic base. The non-ferromagnetic shaft is housed at the centre of the rotor disc and runs through the stator disc. It is supported by bearings on both the ends inside a casing.

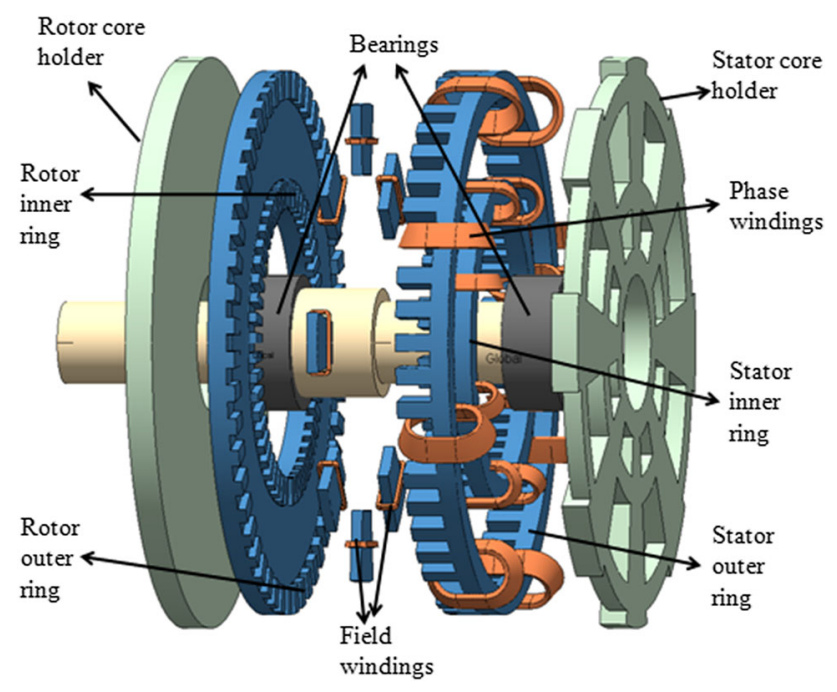

Figure 1. Disc type HSM topology.

\subsection{Stator disc}

The stator is made of two concentric rings. The rings are identical in structure. They have eight equally spaced pole projections as shown in figure 2 . The pole projections are cut to have five teeth each. The concentric stator rings are attached to a core holder made of a non-ferromagnetic material to fix the rings in place

\subsection{Rotor disc}

The rotor is also made of two concentric rings. The inner and outer rings of rotor are placed over the corresponding inner and outer rings of the stator, with matched inner and outer radius. The rotor rings are further attached to a solid disc base that is made of the same material and it houses the bearing shaft as shown in figure 3 .

For a HSM the stator pole pitch spans 'an integer $+1 / 2$, rotor slot pitch. The inner and outer rotor core rings are offset by $1 / 2$ rotor slot pitch, so that the torques developed by both the sections act in the same direction. This is the requirement for unipolar flux.

\subsection{Phase windings and axial flux}

The stator houses eight core-wound concentric windings. They are spaced equally around the ring within the poles. They are excited with a two-phase supply. Figure 4 shows concentric coils 1, 3, 5, 7 for phase A and coils 2, 4, 6, 8 for phase $\mathrm{B}$ wound around the core. Both inner and outer rings are wound with concentric windings in similar patterns. This results in 4 excited poles each around the inner and outer stator. The stator flux that emanates from the coilwound core enters the air gap from the 5 teeth pole face of

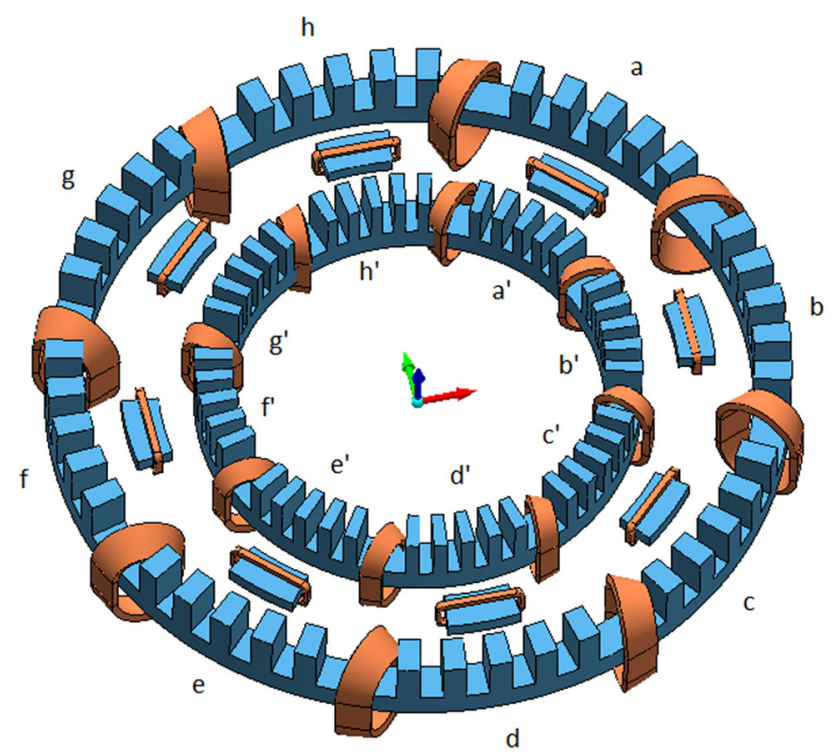

Figure 2. Stator pole projections. 


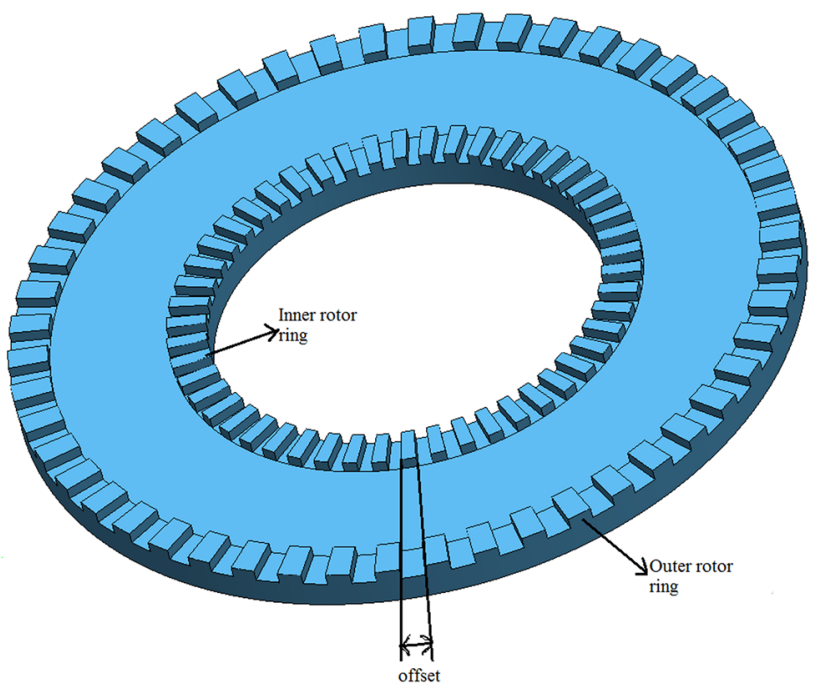

Figure 3. Offset in the ringed rotor cores.

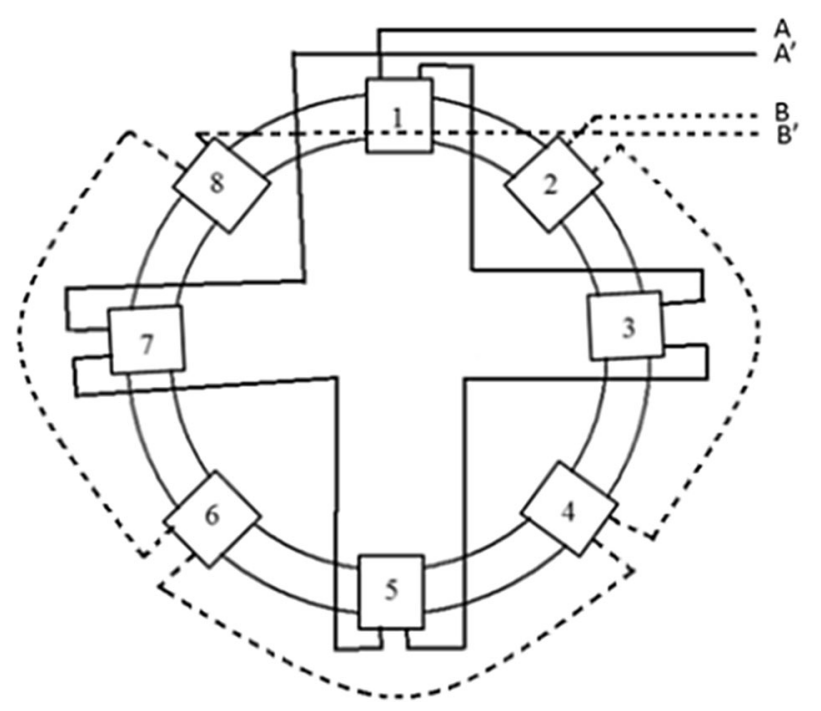

Figure 4. Phase windings connection diagram.

the corresponding inner (or outer) stator. It travels through the corresponding inner (or outer) rotor and returns back through the next excited pole face of the inner (or outer) stator as in figure 5. Hence the excitation flux travels axially from top to bottom (or vice-versa) in the DTHSM, contrary to radial form in cylindrical machine.

\subsection{Field windings and radial homopolar flux}

Field windings are located between the inner and outer stator rings such that the outer and inner stator cores are in unipolar form. This results in circulation of main field flux, always from outer to inner in stator and inner to outer in

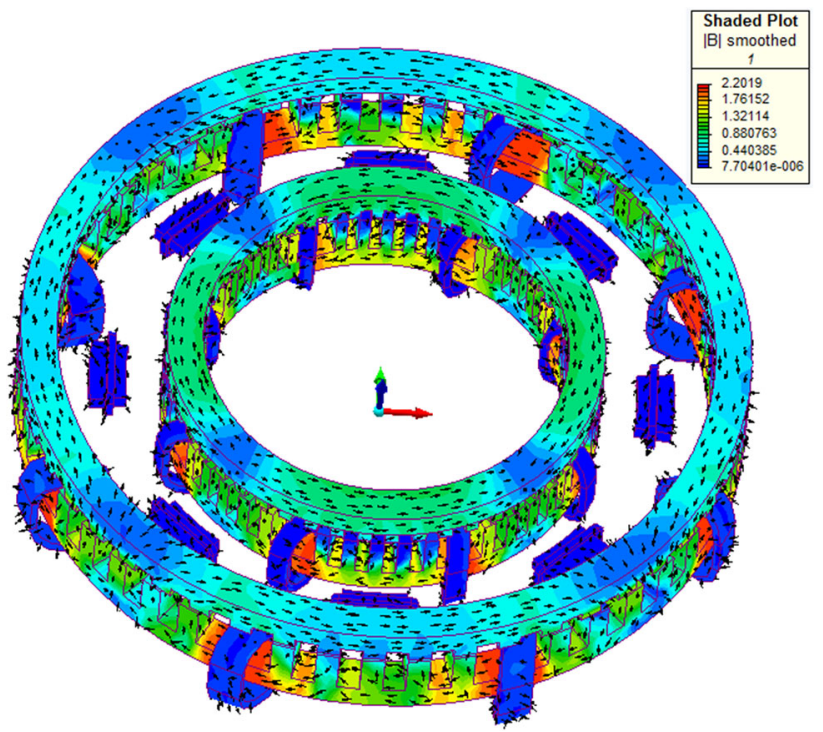

Figure 5. Axial flux distribution when only phase windings are excited.

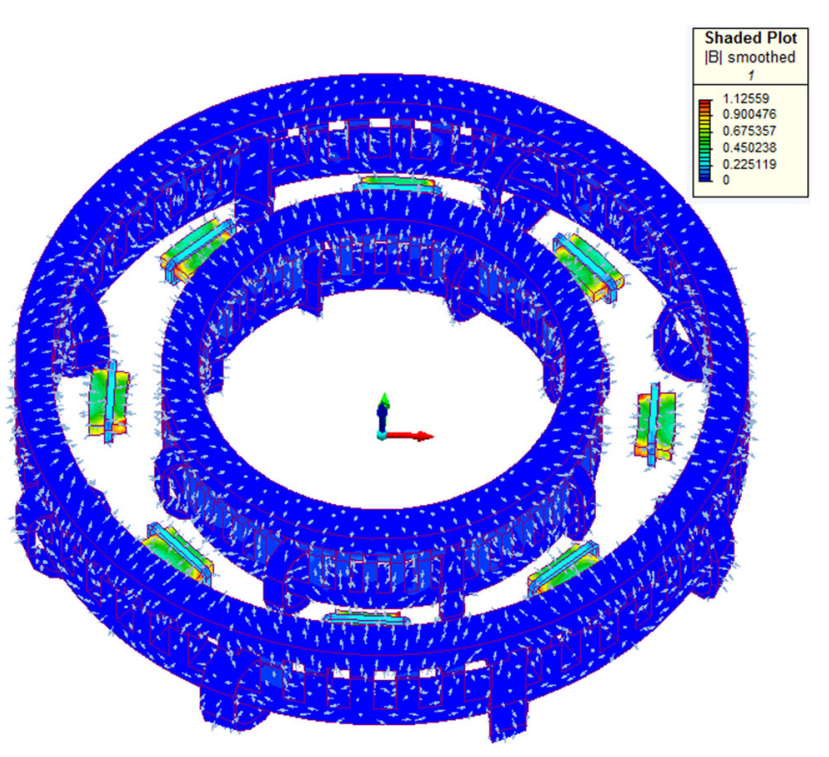

Figure 6. Homopolar flux distribution when only field windings are excited.

rotor or vice-versa depending on the north-south polarity convention used as in figure 6. On the stator side, to circulate unipolar flux in the radial direction, the unipolar flux that ensures from the flux path connects radially all the four rings crossing the air gap twice.

\section{Principle of operation}

The principle of operation is similar to that of any cylindrical HSM. To understand how the principle fits for the disc-type machine, the principle is discussed in detail. 


\subsection{Alignment of stator and rotor teeth}

The design of the machine is in such a way that the five teeth of the pole faces are in any one of all four positions as listed in table 1.

Figure 7 shows the leading and lagging HA pole faces. The consecutive pole faces pass through these four sequences in a cyclic fashion. It leads to two FA, two UA and four HA pole faces in steady state.

\subsection{Motion component}

The HA pole faces provide the maximum torque and this will be the motivation for movement. The leading and lagging phases correspondingly enable the direction in which the motion should occur. The field excitation sets all the poles at the same polarity due to its unipolar nature. Hence the phase excitation should enable the movement.

\subsection{Two-phase excitation}

The phase windings are excited with balanced twophase AC square or sinusoidal voltage to form four poles. A tooth-wound HSM operates on single-phase excitation in half step mode, whereas the core-wound requires at any point of time two-phase excitation. Single-phase excitation will alter the pole count due to core-wound coils. The phase excitation table is as shown in table 2.

When phase A is energized the stator poles a, a' and e, e' are magnetized, say as 'south'; then the poles c, c' and g, g' are magnetized as 'north'. The unipolar rotor ensures attraction and repulsion in the leading and lagging HA poles, respectively, ensuring unidirectional torque. At each phase change as per table 1 , in the sequence 1-2-3-4-1, the rotor moves by $1 / 4$ of a rotor slot pitch. The direction of movement is altered when the excitation sequence is

Table 1. Pole face alignment positions.

\begin{tabular}{lc}
\hline Position & Alignment \\
\hline 1 (180 elec. deg) & Fully aligned (FA) \\
2 (90 elec. deg) & Half aligned (HA) with leading pole faces \\
3 (0 elec. deg) & Unaligned (UA) \\
$4(270$ elec. deg) & Half aligned (HA) with lagging pole faces \\
\hline
\end{tabular}

Table 2. Phase excitation sequence.

\begin{tabular}{lcc}
\hline Steps & Phase A & Phase B \\
\hline 1 & $+\mathrm{V}$ & $-\mathrm{V}$ \\
2 & $+\mathrm{V}$ & $+\mathrm{V}$ \\
3 & $-\mathrm{V}$ & $+\mathrm{V}$ \\
4 & $-\mathrm{V}$ & $-\mathrm{V}$ \\
\hline
\end{tabular}

reversed to $1-4-3-2-1$. The machine requires 200 continuous excitations in a sequence to complete one revolution.

The electromagnetic torque developed is proportional to the phase current, field current, the fundamental component of the permeance variation of a phase and the sine of the angle between the stator pole axis and the nearest rotor tooth axis expressed in electrical radians [22].

\section{Magnetic circuit model}

The magnetic equivalent circuit of the proposed DTHSM is given in figure 8 . The model has three categories of closed mesh circuits, first one in the inner ring, second one in the outer ring and the third one connecting the inner and outer rings through the field excitation. The inner and outer ring mesh circuits provide the closed path for circulation of their respective armature flux. The cross-mesh circuit provides a closed path for the field flux circulation across the inner and outer rings.

The nodes are numbered with the pole face alignment positions as per table 1 in section 3 . The magneto-motive force (mmf) in the windings is $N_{x y} i_{x y}$, and $R_{1 y}, R_{2 y n}$ and $R_{3 y}$ represent the reluctances in the stator core, stator tooth to rotor tooth path along air gap (also vice-versa) and rotor back iron, respectively. Subscripts $x, y$ and $n$ represent phases $\mathrm{A} / \mathrm{B}$, inner/outer ring and node number (position value in table 1), respectively. The reluctance in the field circuit is represented as $R_{\mathrm{f}}$ and $R_{4}$, where $R_{\mathrm{f}}$ and $R_{4}$ are the reluctances of the path connecting inner and outer rings of stator and rotor, respectively. Let $\emptyset_{f m}, \emptyset_{m o}, \emptyset_{m i}$ represent the amount of flux flow along the mesh circuits of field, outer and inner rings, respectively, where $m$ represents the mesh number varying from 1 to 4 in a cyclic fashion.

Reluctances are actually non-linear functions of flux when the $B-H$ relationship of the material is considered. Considering this non-linearity, the generalized mmf equations for the meshes are written as follows:

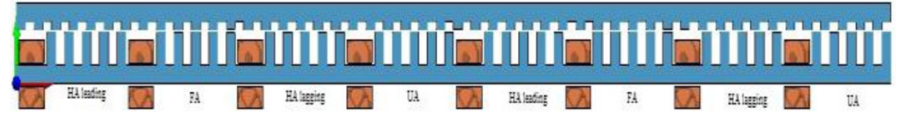

Figure 7. Leading and lagging HA pole faces. 


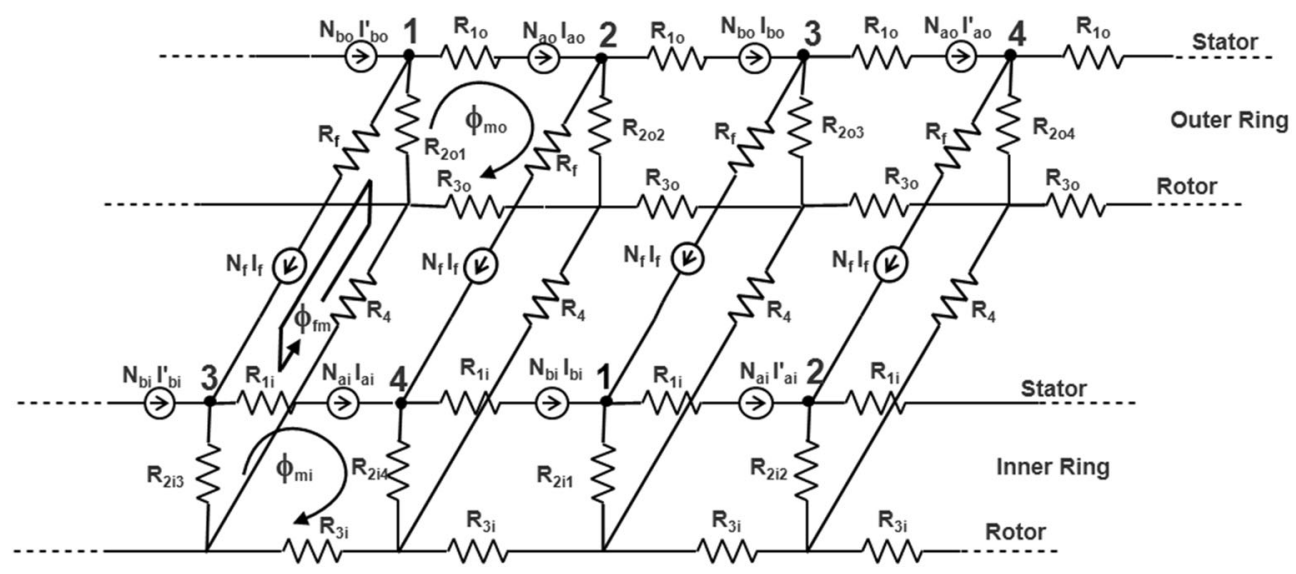

Figure 8. Magnetic equivalent circuit of DTHSM.

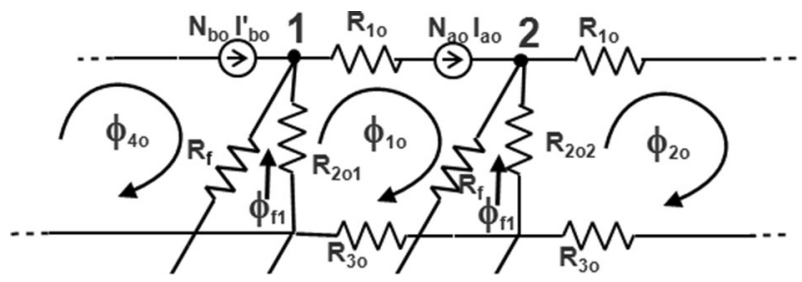

Figure 9. Outer ring equivalent circuit of DTHSM.

$$
\begin{gathered}
N_{m o} i_{m o}=R_{1 o}\left(\emptyset_{m o}\right) \emptyset_{m o}+R_{2 o m}\left(\emptyset_{m o}-\emptyset_{(m+3) o}+\emptyset_{f m}\right) \emptyset_{m o} \\
\quad+R_{2 o(m+1)}\left(\emptyset_{m o}-\emptyset_{(m+1) o}-\emptyset_{f m}\right) \emptyset_{m o}+R_{3 o}\left(\emptyset_{m o}\right) \emptyset_{m o}
\end{gathered}
$$

$$
\begin{gathered}
N_{m i} i_{m i}=R_{1 i}\left(\emptyset_{m i}\right) \emptyset_{m i}+R_{2 i(m+2)}\left(\emptyset_{m i}-\emptyset_{(m+3) i}-\emptyset_{f(m+2)}\right) \emptyset_{m i} \\
+R_{2 i(m+3)}\left(\emptyset_{m i}-\emptyset_{(m+1) i}+\emptyset_{f(m+3)}\right) \emptyset_{m i}+R_{3 i}\left(\emptyset_{m i}\right) \emptyset_{m i},
\end{gathered}
$$

$$
\begin{aligned}
N_{f} i_{f}= & R_{f}\left(\emptyset_{f m}\right) \emptyset_{f m}+R_{2 o m}\left(\emptyset_{m o}-\emptyset_{(m+3) o}+\emptyset_{f m}\right) \emptyset_{m o} \\
& +R_{2 i(m+2)}\left(\emptyset_{m i}-\emptyset_{(m+3) i}-\emptyset_{f m}\right) \emptyset_{m i}+R_{4}\left(\emptyset_{f m}\right) \emptyset_{f m}
\end{aligned}
$$

All $m$ vary from 1 to 4 in a cyclic manner as mentioned earlier. It is to be noted that the variable $n$ is the node number and it is replaced with $m$ and $(m+1) /(m+3)$ as per the mesh number considered. For example mesh ' 1 ' that is between nodes 1 and 2 in the outer ring is shown in figure 9, and 3 and 4 in the inner ring is shown in figure 10. The corresponding mmfs are given in Eqs. (4) and (5). Figure 11 shows the mesh corresponding to the field circuit and Eq. (6) is its mmf expression.

$$
\begin{aligned}
N_{\mathrm{ao}} i_{\mathrm{ao}}= & R_{1 \mathrm{o}}\left(\emptyset_{1 \mathrm{o}}\right) \emptyset_{1 \mathrm{o}}+R_{2 \mathrm{o} 1}\left(\emptyset_{1 \mathrm{o}}-\emptyset_{(4) \mathrm{o}}+\emptyset_{\mathrm{f} 1}\right) \emptyset_{1 \mathrm{o}} \\
& +R_{2 \mathrm{o} 2}\left(\emptyset_{1 \mathrm{o}}-\emptyset_{(2) \mathrm{o}}-\emptyset_{\mathrm{f} 1}\right) \emptyset_{1 \mathrm{o}}+R_{3 \mathrm{o}}\left(\emptyset_{1 \mathrm{o}}\right) \emptyset_{1 \mathrm{o}}
\end{aligned}
$$

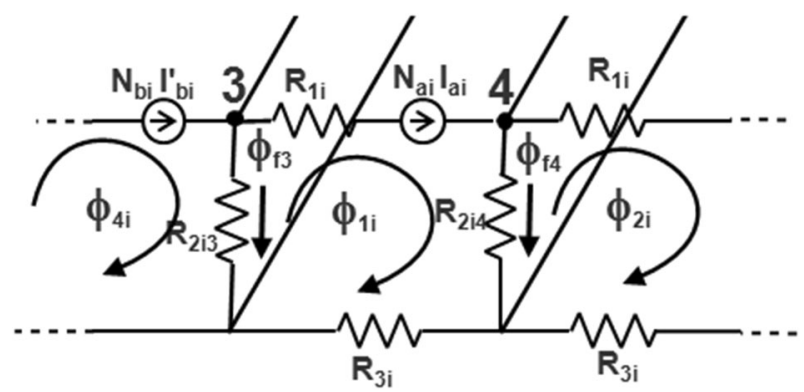

Figure 10. Inner ring equivalent circuit of DTHSM.

$$
\begin{aligned}
N_{\mathrm{ai}} i_{\mathrm{ai}}= & R_{1 \mathrm{i}}\left(\emptyset_{1 \mathrm{i}}\right) \emptyset_{1 \mathrm{i}}+R_{2 \mathrm{i}(3)}\left(\emptyset_{1 \mathrm{i}}-\emptyset_{(4) \mathrm{i}}-\emptyset_{\mathrm{f}(3)}\right) \emptyset_{1 \mathrm{i}} \\
& +R_{2 \mathrm{i}(4)}\left(\emptyset_{1 \mathrm{i}}-\emptyset_{(2) \mathrm{i}}+\emptyset_{\mathrm{f}(4)}\right) \emptyset_{1 \mathrm{i}}+R_{3 \mathrm{i}}\left(\emptyset_{1 \mathrm{i}}\right) \emptyset_{1 \mathrm{i}} \\
N_{\mathrm{f}} i_{\mathrm{f}}= & R_{\mathrm{f}}\left(\emptyset_{\mathrm{f} 1)}\right) \emptyset_{\mathrm{f} 1}+R_{2 \mathrm{o} 1}\left(\emptyset_{1 \mathrm{o}}-\emptyset_{(4) \mathrm{o}}+\emptyset_{\mathrm{f} 1}\right) \emptyset_{1 \mathrm{o}} \\
& +R_{2 \mathrm{i}(3)}\left(\emptyset_{1 \mathrm{i}}-\emptyset_{(4) \mathrm{i}}-\emptyset_{\mathrm{f} 1)}\right) \emptyset_{1 \mathrm{i}}+R_{4}\left(\emptyset_{\mathrm{f} 1}\right) \emptyset_{\mathrm{f} 1} .
\end{aligned}
$$

\section{Determination of model parameters}

\subsection{Determination of reluctances}

For analysis the machine is initially assumed to be linear. The machine dimensions are chosen as per table 3 . The reluctance matrix is constructed from the dimensional relationship and for a given relative permeability. Air gap reluctance is considered to be dependent on the overlap length of the tooth as per Eqs. (7)-(9):

$$
\begin{gathered}
R_{2 y n}=\left[\left(l_{y s t h}+l_{y r t h}\right) /\left(\mu_{0} \mu_{r} t_{w y} l_{y}\right)\right]+\left[l_{g y n} /\left(\mu_{0} t_{w y} l_{y}\right)\right] \\
l_{\mathrm{gon}}=\sqrt{\left(\frac{t_{\mathrm{wo}}}{2}(1+\cos (90(n+2)))\right)^{2}+l_{\mathrm{g}}^{2}}
\end{gathered}
$$




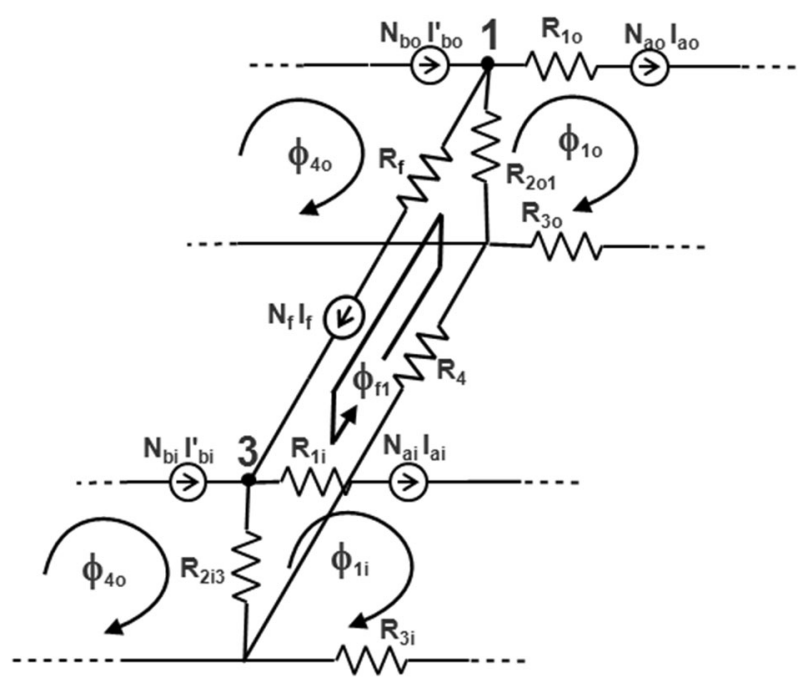

Figure 11. Field equivalent circuit of DTHSM.

Table 3. Disc-type HSM dimensions.

\begin{tabular}{lccccc}
\hline & \multicolumn{2}{c}{ Stator } & & \multicolumn{2}{c}{ Rotor } \\
\cline { 2 - 3 } \cline { 5 - 6 } & $\begin{array}{c}\text { Outer } \\
\text { ring }\end{array}$ & $\begin{array}{c}\text { Inner } \\
\text { ring }\end{array}$ & & Outer ring & $\begin{array}{c}\text { Inner } \\
\text { ring }\end{array}$ \\
\hline Outer diameter (mm) & 200 & 60 & & 200 & 60 \\
Inner diameter (mm) & 100 & 50 & & 100 & 50 \\
Air gap length (mm) & 1 & & & \\
Number of slots & 40 & 50 & & \\
Tooth width (mm) & 6.28 & 3.77 & & 6.28 & 3.77 \\
Slot depth (mm) & 13 & 3 & & \\
Back iron thickness & 7 & 7 & & & \\
$\quad$ (mm) & & & & No \\
Number of turns & 1600 & 800 & & windings \\
& & & &
\end{tabular}

$$
l_{\mathrm{gin}}=\sqrt{\left(\frac{t_{\mathrm{wi}}}{2}(1+\cos (90 n))\right)^{2}+l_{\mathrm{g}}^{2}}
$$

where $y$ is considered as $i$ for inner ring and o for outer ring. As per the alignment condition of stator and rotor tooth at each node $n$, the value of $n$ is chosen as position numbers given in table $1 . l_{\text {gin }}$ and $l_{\text {gon }}$ represent the length of the air gap at nodes $n$ of the inner and outer rings, respectively. Parameter $l_{y}$ represents the length of the inner and outer rings, defined as half of the difference between the inner and outer diameter; $l_{y s t h}$ and $l_{y r t h}$ represent the length of the stator and rotor tooth, respectively; $l_{\mathrm{g}}$ is the air gap length between the stator and rotor and $t_{\mathrm{w} y}$ is the tooth width of the stator and rotor. Figure 12 shows a diagram representing the various tooth dimension quantities for air gap reluctance measurement of the DTHSM. Table 4 provides the reluctances of the core path and air gap. $\mathrm{R}_{2 \mathrm{o} 1}$ and $\mathrm{R}_{2 \mathrm{i} 1}$ are

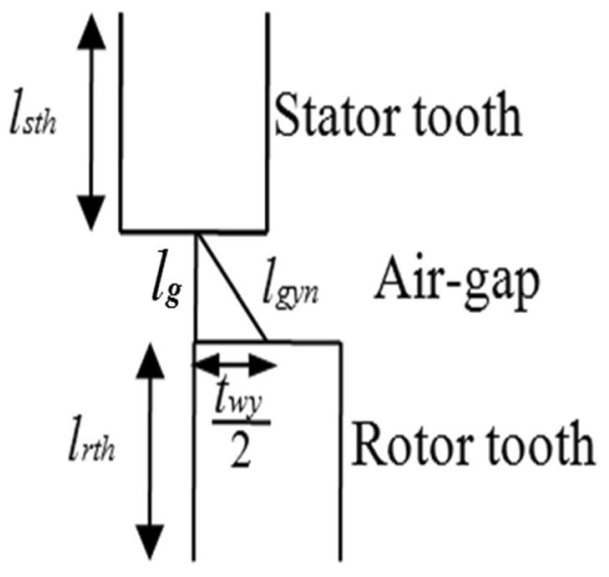

Figure 12. Tooth dimensions for DTHSM.

Table 4. Reluctances of the core path and FA position of air gap.

\begin{tabular}{lc}
\hline Reluctance & Value $\left(\times 10^{5} \mathrm{H}^{-1}\right)$ \\
\hline$R_{1 \mathrm{o}}$ & 8.4821 \\
$R_{3 \mathrm{o}}$ & 8.4821 \\
$R_{1 \mathrm{i}}$ & 4.9107 \\
$R_{3 \mathrm{i}}$ & 4.9107 \\
$R_{\mathrm{f}}$ & 806.94 \\
$R_{4}$ & 11.523 \\
$R_{2 \mathrm{o} 1}$ & 2.1331 \\
$R_{2 \mathrm{i} 1}$ & 3.6844 \\
\hline
\end{tabular}

obtained when the stator and rotor poles are in fully aligned position.

\subsection{Determination of mesh and air gap flux}

The flux in the air gap of DTHSM is obtained by solving Eqs. (1)-(3) for the following data. The permeability of the material is chosen to be 1000 . The phase currents are kept at $0.4 \mathrm{~A}$ and field current is kept at $5 \mathrm{~A}$. Field is considered to be wound on a core covering a volume of $50 \%$ of pole area between the inner and outer rings with 200 turns. The excitation sequence is chosen such that, like poles are formed in the inner and outer HA pole phases. Flux flow in the air gap at nodes 1 and 3 of outer and inner rings respectively is shown in figure 13. The exercise is repeated for various rotor positions from HA leading to HA lagging to obtain the flux variation with rotor position. Table 5 provides the relationship between air gap flux and rotor position.

It is observed from table 5 that the flux is maximum at the FA position and minimum at the UA position. There is a change in the flux pattern of the inner ring due to the shift in the rotor outer and inner ring tooth positions as indicated in section 2 . 


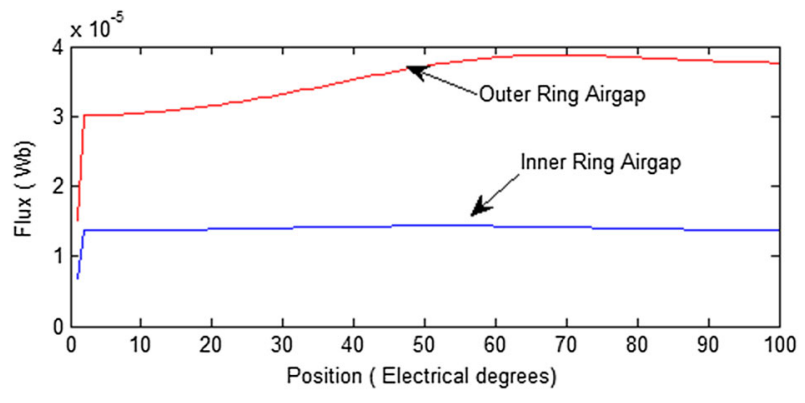

Figure 13. Air gap flux.

Table 5. Air gap flux variation for different rotor positions.

\begin{tabular}{lcc}
\hline & \multicolumn{2}{c}{ Air gap flux $(\mathrm{mWb})$} \\
\cline { 2 - 3 } Rotor position (electrical degrees) & Outer & Inner \\
\hline 90 & 48.8 & 10.16 \\
0 & 6 & 11.7 \\
270 & 55.2 & 9.2 \\
180 & 61.6 & 4 \\
\hline
\end{tabular}

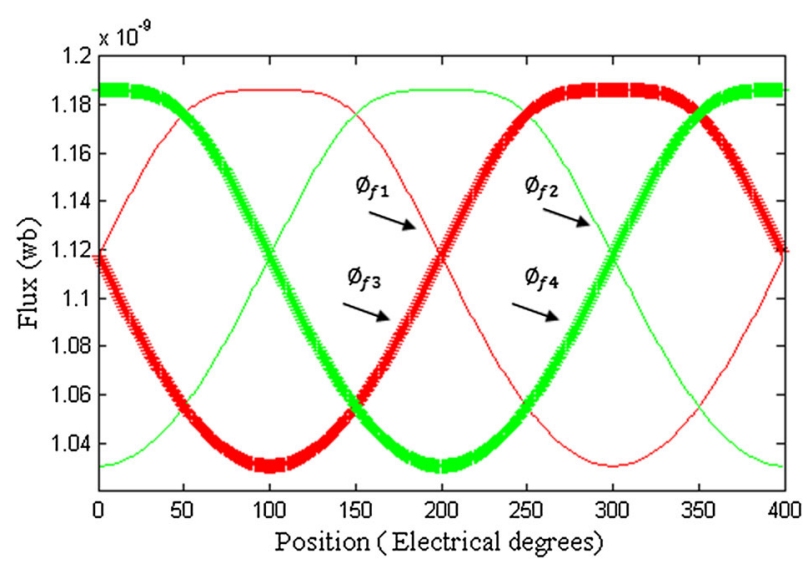

Figure 14. Mesh flux in the field.

Figure 14 shows the mesh flux $\emptyset_{\mathrm{f} m}$ waveform when field windings are only excited. $\emptyset_{\mathrm{f} 1}, \emptyset_{\mathrm{f} 2}, \emptyset_{\mathrm{f} 3}, \emptyset_{\mathrm{f} 4}$ are the four field mesh fluxes as indicated in figure 8 as the rotor position varies from $0^{\circ}$ to $360^{\circ}$. This indicates that the air gap flux produced by the machine is unipolar and has a maxima and minima at aligned and unaligned positions respectively. Also individual field coils see position dependent reluctance and motional emf. But since, all the eight field coils are connected in series, the net emf add up to zero at all rotor positions as they see similar flux pattern in a cyclic manner.

The air gap flux variation at HA positions when the field excitation is increased is provided in table 6 . It indicates
Table 6. Air gap flux variation for different $I_{\mathrm{f}}$.

\begin{tabular}{lcr}
\hline & \multicolumn{2}{c}{ Air gap flux $(\mathrm{mWb})$} \\
\cline { 2 - 3 } Field current (A) & Outer & Inner \\
\hline 0 & 36.8 & 9.6 \\
1 & 60.8 & 11.2 \\
2 & 70.4 & 12.8 \\
3 & 73.6 & 13.6 \\
4 & 80 & 15.2 \\
5 & 86.4 & 16.8 \\
6 & 91.2 & 17.6 \\
7 & 99.2 & 18.4 \\
8 & 104 & 19.2 \\
9 & 108.8 & 20.8 \\
10 & 116.8 & 21.6 \\
\hline
\end{tabular}

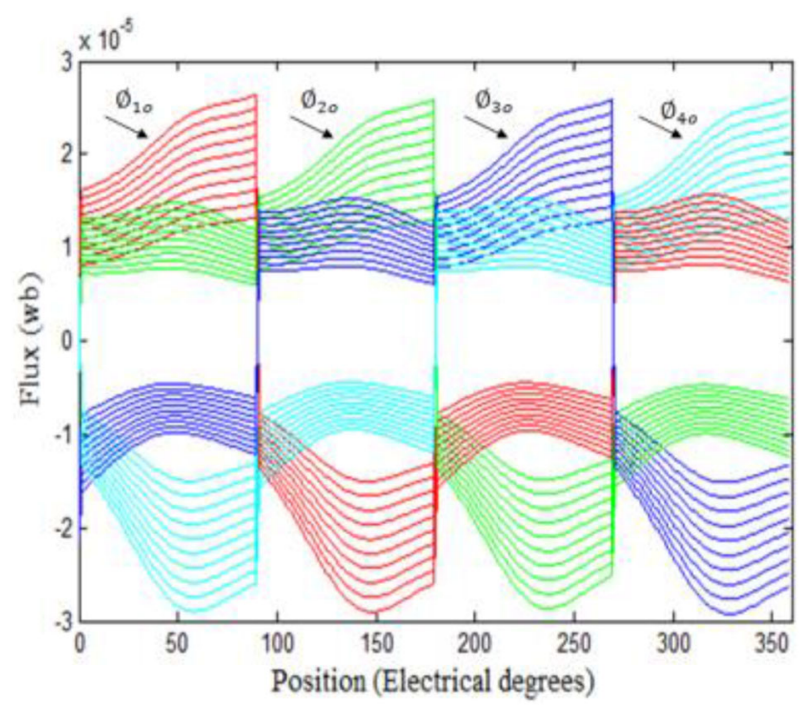

Figure 15. Mesh fluxes in the outer ring.

increase of flux in the air gap of the machine as field current increases.

Figure 15 gives the mesh flux $\left(\emptyset_{m o}\right)$ wave shapes in the outer machine as indicated in figure 8 , when both the phases are excited as in table 2 as the rotor position moves from $0^{\circ}$ to $360^{\circ}$ and as the field current is varied from 1 to $10 \mathrm{~A}$. The different colours in the waveforms are coded as red for $\emptyset_{10}$, green for $\emptyset_{20}$, blue for $\emptyset_{30}$ and cyan for $\emptyset_{40}$. Similarly, figure 16 gives the mesh flux $\left(\emptyset_{m \mathrm{i}}\right)$ wave shapes in the inner machine. The different colours in the waveforms are coded as red for $\emptyset_{3 \mathrm{i}}$, green for $\emptyset_{4 \mathrm{i}}$, blue for $\emptyset_{1 \mathrm{i}}$ and cyan for $\emptyset_{2 \mathrm{i}}$.

The increase of flux in the air gap either due to field current or phase current improves the torque producing capability of the machine. This is discussed in section 6 . 


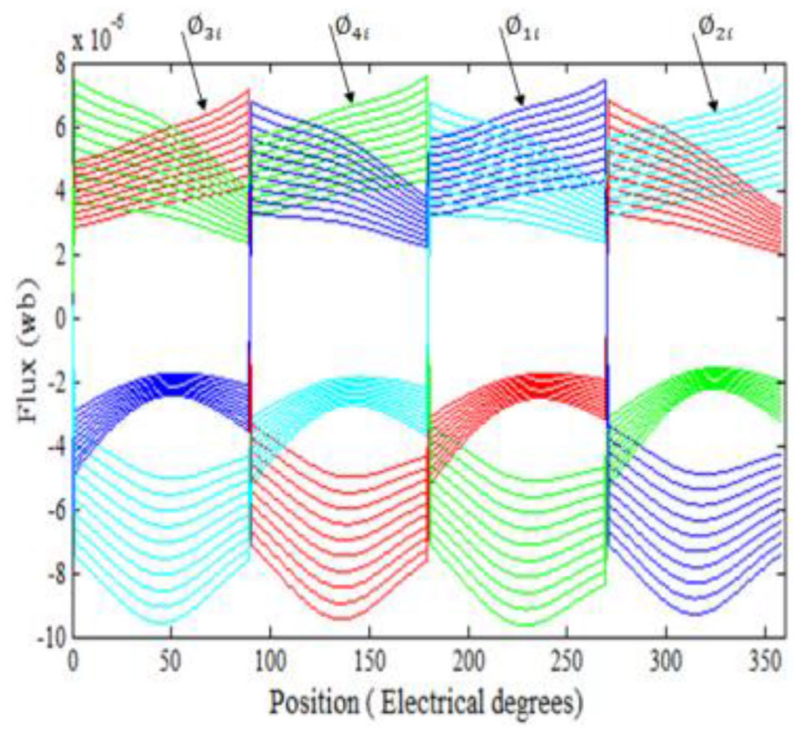

Figure 16. Mesh fluxes in the inner ring.

\subsection{Determination of magnetic circuit parameters}

A detailed description of field and phase flux linkages for HSM is explained in [22]. The same approach is used in the proposed DTHSM to determine the flux linkages and inductance.

The field mmf in each section is taken as $N_{\mathrm{f}} i_{\mathrm{f}}$. Neglecting all reluctances except air gap, the flux linkage is

$$
\begin{aligned}
& \lambda_{\mathrm{a} 1}=\left[L_{0}+L_{1} \cos \left(N_{\mathrm{r}} \theta\right)\right] i_{\mathrm{f}} \\
& \lambda_{\mathrm{a} 2}=\left[L_{0}-L_{1} \cos \left(N_{\mathrm{r}} \theta\right)\right] i_{\mathrm{f}}
\end{aligned}
$$

where $\lambda_{\mathrm{a} 1}$ is the flux linkage of coil 1 of phase $\mathrm{A}, \lambda_{\mathrm{a} 2}$ is the flux linkage of coil 2 of phase A, $N_{\mathrm{r}}$ is the number of rotor tooth and $I_{\mathrm{f}}$ is the field current. Taking into account the direction of fluxes, the net flux linkage in phase A (due to field excitation only) is given as

$$
\lambda_{\mathrm{a}}^{\prime}=\lambda_{\mathrm{a} 1}-\lambda_{\mathrm{a} 2}=i_{\mathrm{f}} L_{1} \cos \left(N_{\mathrm{r}} \theta\right) .
$$

The flux linkage due to phase currents only with $i_{\mathrm{f}}=0$ is given as

$$
\lambda_{\mathrm{a}}^{\prime \prime}=L_{\mathrm{a}} i_{\mathrm{a}} .
$$

Total flux linkage of phase A due to $i_{\mathrm{f}}$ as well as $i_{\mathrm{a}}$ is

$$
\lambda_{\mathrm{a}}=i_{\mathrm{f}} L_{1} \cos \left(N_{\mathrm{r}} \theta\right)+L_{\mathrm{a}} i_{\mathrm{a}} .
$$

Similarly for phase B, which is lagging in space by $90^{\circ}$, the total flux linkage is

$$
\lambda_{\mathrm{b}}=i_{\mathrm{f}} L_{1} \cos \left(N_{\mathrm{r}} \theta-\frac{\pi}{2}\right)+L_{\mathrm{b}} i_{\mathrm{b}} .
$$

Table 7. Inductance and torque constant values.

\begin{tabular}{llc}
\hline & $L(\mathrm{H})$ & $K_{\mathrm{m}}(\mathrm{m} \mathrm{Nm} / \mathrm{A})$ \\
\hline Outer & 1.1 & 1.4 \\
Inner & 0.2312 & 0.4512 \\
\hline
\end{tabular}

Also, $L_{\mathrm{a}}=L_{\mathrm{b}}=L$ where $\mathrm{L}$ is the total inductance per phase. The interaction between phase A and phase B has not been accounted as their values are minimal.

The emf or torque constant $\left(K_{\mathrm{m}}\right)$ of the machine has two terms, namely the field producing current and the positiondependent inductance coefficient. The angle-dependent value of air gap inductance in this machine is actually the average difference between the unaligned and aligned inductances. The values of inductances per phase and motor constant values of the outer and inner machine are tabulated in table 7 . These values are obtained by noting the voltage induced in the coils of the inner rings, outer rings and field coils, when the phase coils are excited only one at a time and only field coils are excited.

\section{Performance prediction}

The dynamic equation of the HSM as given in $[1,2]$ is considered here with the parameters.

$$
\begin{gathered}
\frac{\mathrm{d} i_{a}}{\mathrm{~d} t}=\left[v_{\mathrm{a}}-R i_{\mathrm{a}}+K_{\mathrm{m}} i_{\mathrm{f}} \omega \sin \left(N_{\mathrm{r}} \theta\right)\right] / L \\
\frac{\mathrm{d} i_{\mathrm{b}}}{\mathrm{d} t}=\left[v_{\mathrm{b}}-R i_{\mathrm{b}}-K_{\mathrm{m}} i_{\mathrm{f}} \omega \cos \left(N_{\mathrm{r}} \theta\right)\right] / L \\
\frac{\mathrm{d} \omega}{\mathrm{d} t}=\left[-K_{\mathrm{m}} i_{\mathrm{f}} i_{\mathrm{a}} \sin \left(N_{\mathrm{r}} \theta\right)+K_{\mathrm{m}} i_{\mathrm{f}} i_{\mathrm{b}} \cos \left(N_{\mathrm{r}} \theta\right)-B \omega-T_{\mathrm{L}}\right] / J \\
\frac{\mathrm{d} \theta}{\mathrm{d} t}=\omega
\end{gathered}
$$

where $v_{\mathrm{a}}, v_{\mathrm{b}}$ and $i_{\mathrm{a}}, i_{\mathrm{b}}$ are the voltages and currents in phase $\mathrm{A}$ and B, respectively, $i_{\mathrm{f}}$ is the field current, $K_{\mathrm{m}}$ is the motor torque constant, $\omega$ is the rotor angular velocity, $\theta$ is the rotor angular position, $B$ is the viscous friction coefficient and $J$ is the inertia of the rotor; $R$ and $L$ are, respectively, resistance and self-inductance of phase windings. The parameters of the DTHSM are given in table 8. The values of $L$ and $K_{\mathrm{m}}$ are obtained as discussed earlier for table 7 . $J$ and $B$ are obtained from the simulation results using Magnet software with the model being constructed using the dimensions given as per table 3 . The mutual magnetic coupling between phases and effect of detent torque are neglected because their contribution is very small in motor dynamics. The motor model specified by (16)-(19) is simulated. 
Table 8. Disc-type HSM parameters.

\begin{tabular}{lcc}
\hline & \multicolumn{2}{c}{ Value } \\
\cline { 2 - 3 } Parameters & Outer & Inner \\
\hline$L(\mathrm{H})$ & 1.1 & 0.23 \\
$R(\Omega)$ & 140 & 72 \\
$J$ & $0.001 \mathrm{~kg} \mathrm{~m}^{2}$ & \\
$K_{\mathrm{m}}(\mathrm{m} \mathrm{Nm} / \mathrm{A})$ & 1.4 & 0.4512 \\
$N_{\mathrm{r}}$ & 50 & \\
$B(\mathrm{~N} \mathrm{~m} \mathrm{~s} / \mathrm{rad})$ & 0.01 & \\
\hline
\end{tabular}

(a)

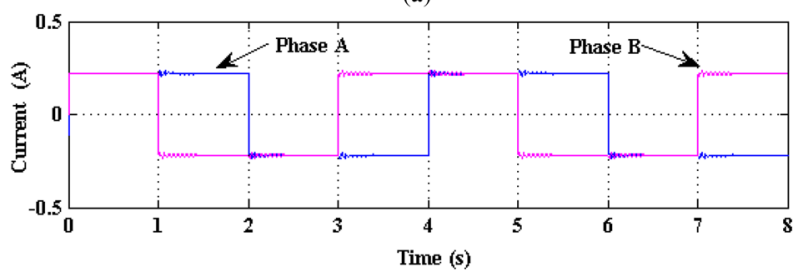

(b)

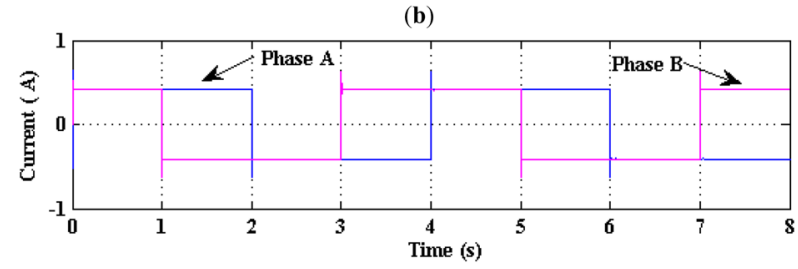

Figure 17. Current waveform: (a) outer and (b) inner.

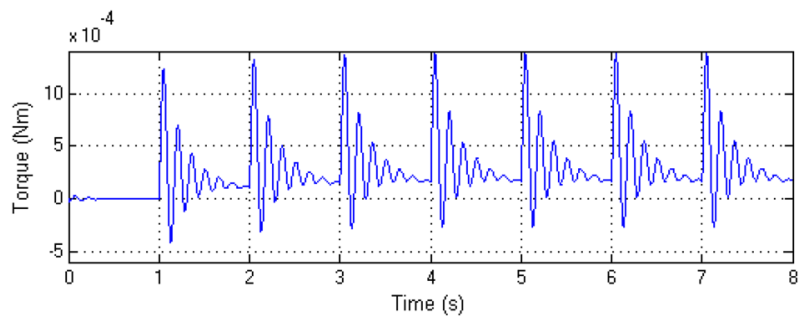

Figure 18. Torque under no-load condition.

The simulation results showing the current in both the phases of inner and outer rings, torque and position of the DTHSM when excited with a pulsed voltage source of $30 \mathrm{~V}$ at $0.25 \mathrm{~Hz}$ frequency are given in figures 17-19. Developed torque waveform in figure 18 exhibits ripples, which is also seen in the phase current and position waveforms. For every step, the motor torque approaches zero. The values of developed torque for various speeds are tabulated in table 9.

As the field current increases, the torque and position ripples settle faster. The values of torque for various field

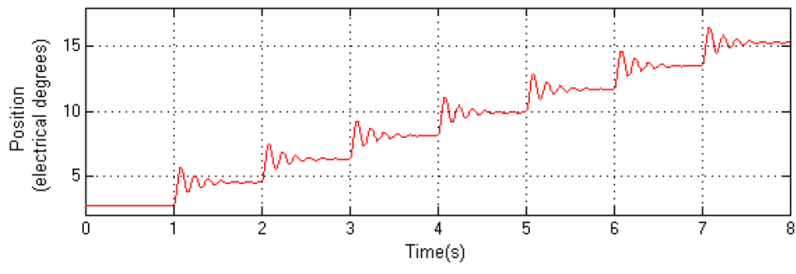

Figure 19. Position waveform.

Table 9. Variation of torque with speed.

\begin{tabular}{lcc}
\hline Excitation frequency $(\mathrm{Hz})$ & Speed $(\mathrm{rpm})$ & Torque $(\mathrm{Nm})$ \\
\hline 1 & 1.2 & 0.17 \\
2 & 2.4 & 0.14 \\
3 & 3.6 & 0.18 \\
4 & 4.8 & 0.17 \\
5 & 6 & 0.168 \\
10 & 12 & 0.14 \\
\hline
\end{tabular}

Table 10. Variation of torque with field mmf.

\begin{tabular}{lc}
\hline Field $\mathrm{mmf}\left(\times 10^{3} \mathrm{AT}\right)$ & Torque $(\mathrm{Nm})$ \\
\hline 0.2 & 0.03 \\
1 & 0.17 \\
2 & 0.34 \\
3 & 0.51 \\
4 & 0.68 \\
5 & 0.84 \\
6 & 1 \\
10 & 1.5 \\
20 & 3 \\
22 & 3.6 \\
\hline
\end{tabular}

mmfs are tabulated in table 10. It is observed that as the field ampere turns increase, the developed torque also increases. Also, the ripples in the torque, current and position waveforms settle at a faster rate.

It is found that about 7320 turns of AWG 22 copper conductor can be provided for the field winding in the space available between the inner and outer rings of the proposed DTHSM. Hence the field mmf can be further increased to be more than 22000 AT if a complete thermal study of the machine is conducted.

\section{Experimental validation}

A prototype hardware of the DTHSM is constructed to validate the simulation results. Figure 20 shows the construction of stator core. The stator core teeth are CNC cut 


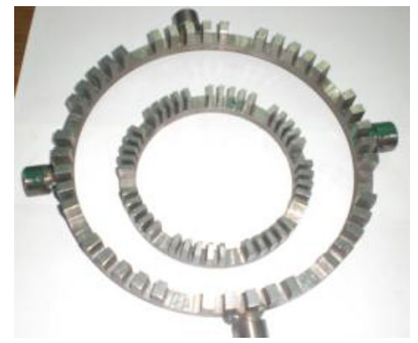

Figure 20. Outer and inner stator cores for the hardware prototype.

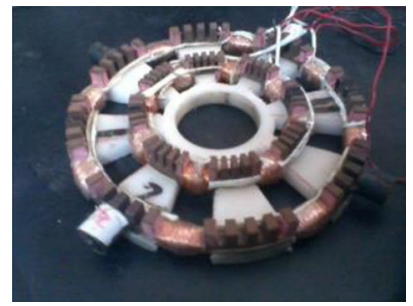

Figure 21. Stator core with windings fitted into the core holder.

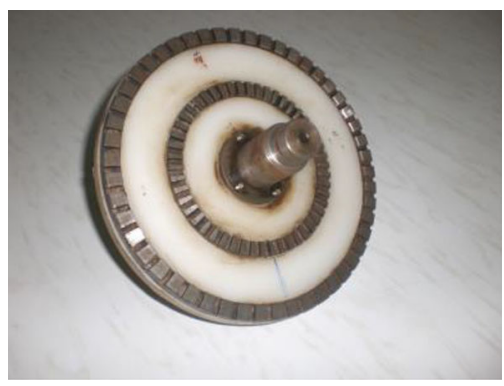

Figure 22. Rotor set-up.

from a single piece of core material with $300 \mathrm{~mm}$ diameter and $25 \mathrm{~mm}$ thickness. The milled stator core is cut into two concentric rings and windings are wound concentrically and fixed into the stator core holder as shown in figure 21 . The rotor rings attached to the core holder and bearings are shown in figure 22.

A hardware schematic for the experimental set-up of the prototyped DTHSM is shown in figure 23. A UC3717 stepper motor driver in conjunction with LM298 IC is used to excite the machine. The clock pulse for the driver circuit is given using a $30-\mathrm{MHz}$ function generator. A current probe of $10 \mathrm{mV} / \mathrm{A}$ is used to capture the current wave shape of the machine. The outer ring phase current waveform measured for a square wave excitation of $30 \mathrm{~V}$ at 0.25 and $1 \mathrm{~Hz}$ frequency is given in figures 24 and 25 .

It was observed that under no-load condition, at various excitation frequencies the phase current waveforms exhibit

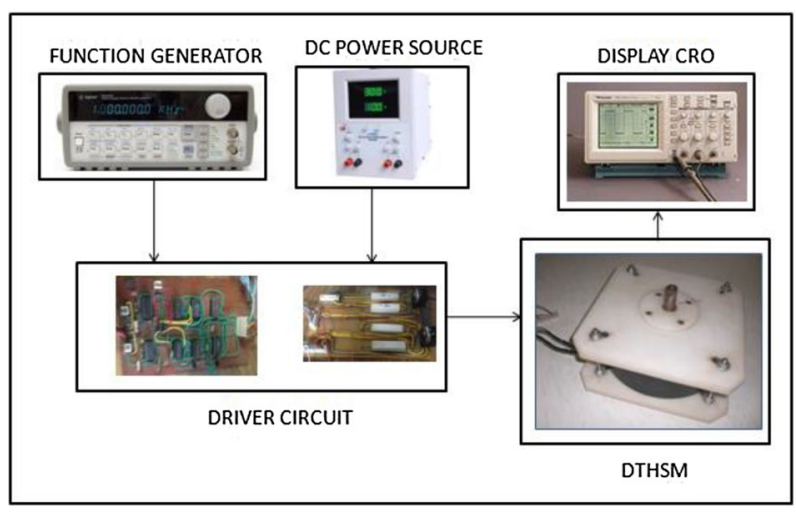

Figure 23. Schematic experimental set-up.

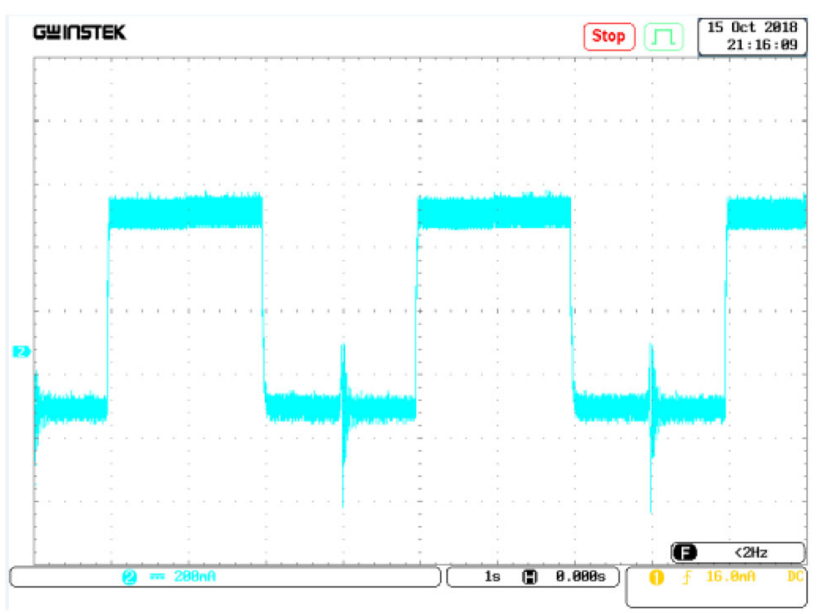

Figure 24. Current at $0.25 \mathrm{~Hz}$ excitation frequency.



Figure 25. Current at $1 \mathrm{~Hz}$ excitation frequency.

ripples. The speed vs torque characteristics of the DTHSM are given in table 11. Torque is measured using a brake drum loading arrangement. 
Table 11. Variation of torque with speed.

\begin{tabular}{lcc}
\hline $\begin{array}{l}\text { Excitation } \\
\text { frequency }(\mathrm{Hz})\end{array}$ & $\begin{array}{c}\text { Speed } \\
(\mathrm{rpm})\end{array}$ & $\begin{array}{c}\text { Max. torque } \\
(\mathrm{Nm})\end{array}$ \\
\hline 1 & 1.2 & 0.171 \\
2 & 2.4 & 0.117 \\
3 & 3.6 & 0.177 \\
4 & 4.8 & 0.174 \\
5 & 6 & 0.171 \\
10 & 12 & 0.142 \\
20 & 24 & 0.194 \\
30 & 36 & 0.142 \\
40 & 48 & 0.222 \\
50 & 60 & 0.177 \\
100 & 120 & 0.052 \\
\hline
\end{tabular}

\section{Conclusion}

The paper has presented the working and analysis of a novel DTHSM suitable for applications where a compact size is needed. A field circuit model is successfully employed for the analysis of the machine. The conceptual design and analysis of the proposed machine have been verified by experimental tests on a prototype. The experimental and simulation results were matched for the inductance values, current wave shape and torque and have been found to be closely correlated. The inductance values found by simulation, as given in table 8 , are matched to experimental values found to be $L($ outer $)=1.9 \mathrm{H}$ and $L$ (inner) $=0.29 \mathrm{H}$. The similarities in the current wave shapes of the simulation and experimental values are matched. Tables 9 and 11 show the correlation of simulation and experimental torque values. The torque capability of the DTHSM can be improved if the field excitation is increased as presented in table 10 .

The proposed DTHSM uses field coils; instead, if magnets are used, it has the advantage of increasing the magnet area between the inner and outer stator, so that increase in field flux and thus increased torque can be achieved. In addition, the proposed DTHSM has the following constructional advantages:

1. The concentric armature windings are simple to wind than distributed windings and are hence cost effective.

2. The modular stator-rotor assembly can be stacked to improve the power rating of the machine.

3. This type of construction is an attractive alternative to the cylindrical type machine as this axial flux machine can be used in applications where compact design is suited. Compactness is achieved through less core area and concentrated windings. Also the DTHSM has no windings or PMs in the rotor, making it a light weight machine.

\section{References}

[1] Kenjo T 1984 Stepping motors and their microprocessor controls. New York: Oxford University Press, pp. 67-69
[2] Acarnely P 2002 Stepping motors: a guide to theory and practice, 4th ed. London, UK: Institute of Electrical Engineers, pp. 2-35

[3] Athani V V 2005 Stepper motor fundamentals, applications and design. New York: New Age International Publisher, pp. 23-45

[4] Capponi F G, Donato G D and Caricchi F 2012 Recent advances in axial-flux permanent-magnet machine technology. IEEE Trans. Ind. Appl. 48: 2190-2204

[5] Jin P, Yuan Y, Xu Q, Fang S, Lin H and Ho S L 2015 Analysis of axial-flux Halbach permanent-magnet machine. IEEE Trans. Magn. 51: 1-4

[6] Gieras J F, Wang R and Kamper M J 2008 Axial flux permanent magnet brushless machines, 2nd ed. New York, NY, USA: Springer, pp. 29-67

[7] Mahmoudi A, Kahourzade S, Rahim N A, Hew W P and Uddin M N 2014 Design, analysis, and prototyping of a novel-structured solid-rotor-ringed line-start axial-flux permanent-magnet motor. IEEE Trans. Ind. Electron. 61: $1722-1734$

[8] Rahman K M, Patel N R, Ward T G, Nagashima J M, Caricchi F and Cresimbini F 2006 Application of direct-drive wheel motor for fuel cell electric and hybrid electric vehicle propulsion system. IEEE Trans. Ind. Appl. 42: 1185-1192

[9] Gonzalez D A, Tapia J A and Bettancourt A L 2007 Design consideration to reduce cogging torque in axial flux permanent magnet machines. IEEE Trans. Magn. 43: 3435-3440

[10] Aydin M, Huang S and Lipo T A 2010 Design, analysis, and control of a hybrid field-controlled axial-flux permanentmagnet motor. IEEE Trans. Ind. Electron. 57: 78-87

[11] Tsao P, Senesky M and Sanders S R 2003 An integrated flywheel energy storage system with homopolar inductor motor/generator and high-frequency drive. IEEE Trans. Ind. Appl. 39: 1710-1725

[12] Aydin M, Zhu Z Q, Lipo T A and Howe D 2007 Minimization of cogging torque in axial-flux permanent-magnet machines: design concepts. IEEE Trans. Magn. 43: 3614-3622

[13] Huang S, Luo J, Leonardi F and Lipo T A 1998 A general approach to sizing and power density equations for comparison of electrical machines. IEEE Trans. Ind. Appl. 34: 92-97

[14] Madhavan R and Fernandes B G 2013 Axial flux segmented SRM with a higher number of rotor segments for electric vehicles. IEEE Trans. Energy Convers. 28: 203-213

[15] Kano Y, Kosaka T and Matsui N 2010 A simple nonlinear magnetic analysis for axial-flux permanent-magnet machines. IEEE Trans. Ind. Electron. 28: 2124-2133

[16] Fei W and Luk P C K 2009 An improved model for the backEMF and cogging torque characteristics of a novel axial flux permanent magnet synchronous machine with a segmental laminated stator. IEEE Trans. Magn. 45: 4609-4612

[17] Chen A, Nilssen R and Arne Nysveen 2010 Performance comparisons among radial-flux, multistage axial-flux, and three phase transverse-flux PM machines for down hole applications. IEEE Trans. Ind. Appl. 46: 779-789

[18] Suk Kwon T, Sul S and Alberti Land Bianchi N 2009 Design and control of an axial-flux machine for a wide flux-weakening operation region. IEEE Trans. Ind. Appl. 45: 1258-1266

[19] Javadi S and Mirsalim M 2010 Design and analysis of $42 \mathrm{~V}$ coreless axial-flux permanent magnet generators for automotive applications. IEEE Trans. Magn. 46: 1015-1023 
[20] Fei W, Luk P C K and Jinupun K 2010 Design and analysis of high-speed coreless axial flux permanent magnet generator with circular magnets and coils. IET Electr. Power Appl. 4: 739-747

[21] Kowal D, Sergeant P, Dupre L and Van den Bossche A 2010

Comparison of non-oriented and grain-oriented material in an axial flux permanent-magnet machine. IEEE Trans. Magn. 4: 279-285

[22] Venkataratnam K 2012 Special electrical machines. India: Universities Press (India) Private Ltd, pp. 5-65 